\title{
An RRA Case Study: the Cotton Project in The Gambia
}

\author{
ODA Food Strategy Team
}

During a recent consultancy to The Gambia by a team of four expatriate planners, a rapid appraisal was carried out to assess the progress of a project designed to increase cotton production in Upper River and MacCarthy Island Divisions. This appraisal was carried out over a period of five days by members of a Food Strategy Team (FST)', sponsored by the Overseas Development Administration of the UK. In this article discussion is confined to the methodology of the appraisal rather than its findings, for which the interested reader should refer to the FST's report. ${ }^{2}$

Although the FST's terms of reference involved an examination of the production, distribution and consumption of food in all its aspects, including institutional factors, the close inter-relationships between food crops and those grown predominantly for cash and export cannot be ignored. Such crops, loosely termed 'cash crops', compete with food crops not only for farmers' labour, land and other inputs but at national level for extension services, marketing facilities, scarce administrative manpower and government subsidies. In The Gambia, groundnuts which cover about one half of the cultivated area, have been the most important crop produced for cash incomes and export but, in addition, in the mid 1970 s, a project was instituted to encourage the production of cotton in the eastern part of the country as part of the policy of agricultural diversification adopted by the Government. In view of the trade-offs and complementaries of 'cash crops' and food crops an evaluation of the effectiveness of the cotton project was essential to a food strategy.

The impact of the project has been small, with only 3,300 hectares planted after six years of operation and investment. Farmers were supplied with seed, fertiliser and pesticides and the ratio of extension workers to farmers was higher than in other parts of the country.

The objective of the rapid appraisal of the cotton project was to identify constraints in its expansion, to examine the distribution of its benefits between and within households, and to assess its potential as an alternative 'cash crop' to groundnuts. It had been an

\footnotetext{
The team consisted of four planners provided by the ODA. At notime were more than two members of the team involved in the rapid appraisal of the Cotton Project. The views expressed represent those of the individual team members and are not necessarily those of ODA

${ }^{2}$ The Government of The Gambia/Overseas Development Admin-
} istration, 1981. The Gambia Food Strategy Report, Parts 1 and 11. original objective of the cotton project that farmers should, in addition, extend their area under cultivation by use of draught power.

The rapid appraisal uncovered three general points of significance for a national food strategy. First, it was confirmed that farmers give priority to their food crops, particularly in terms of their labour. This is a common finding in many developing countries. Second, cotton is grown as a cash crop by individual farmers and not often as an addition to but rather instead of groundnuts. Third, crop marketing facilities frequency of buying points and their timing and reliabilities in relation to the buying of other crops-also influence farmers' choice of cropping patterns.

As a result of the appraisal certain patterns emerged with respect to the recruitment and payment, and sexual division, of labour. As information was also derived on who grew cotton (predominantly male household heads and their immediate male relatives) and who were generally denied access to inputs and information (the women), it was possible to make firm statements about the distribution of benefits of the project. Although such findings could not be supported by quantitative evidence (which would take a great deal of time and effort to collect), the patterns were so clear as to make such data less than essential. The project administration monitored its participants very closely so that 'leakages' of benefits outside the designed project participants would not have been widespread.

One important factor contributed to the success of this appraisal, which uncovered in a short period much information of direct relevance to project planning. This is that the principal investigators were complementary in terms of their expertise and object ives: one, a female expatriate sociologist, had carried out extensive rural research in The Gambia and on the sexual division of labour in particular (see Dey 1980). Another, a male expatriate agricultural economist (not a member of the FST) and a member of the Planning Unit of the Ministry of Agriculture, was conducting at the time of the appraisal a brief quantitative survey among 20 farmers of yields, area planted, labour and draught animal input and use of fertiliser and pesticides. This survey, using extension agents in ten project 'circles' as enumerators and inviting them to select two of their farmers randomly 
as respondents, was intended as a brief exercise to gather quantitative data in preparation for a more comprehensive survey the following year.

The Planning Unit survey gave two important advantages to the FST survey. The first was that it provided a structure to the investigation: a timetable and a geographical spread of respondents. Secondly, it gave valuable quantitative data that could be held in mind during questioning: data, first, on area planted gave an idea of the scale of operation, second, on yields indicated the degree of success of the farmer during the crop year and third, on labour input by operation (and whether labour used was family or hired) showed how the farmer had organised his work priorities during the year, and also how far a belated or inadequate labour input may have contributed to poor yields. In African countries, in contrast to Asian countries, land areas have generally not been measured as a result of registration, and farmers do not know the area of their holdings. The prior availability of area data in this case, even if for one crop, enabled an approach to the respondent with an important understanding of his scale of operation, and with a knowledge that on return from the field calculations on profitability (gross margins) could be made and compared with other crop enterprises (with information already available) so testing farmers' assertions about the relative profitability of crops. Availability of labour input data in this case also enabled a quantitative 'test' of farmers' comments about the relative labour input and 'peakiness' of cotton compared to other crops.

After checking the questionnaires in the hands of the extension agent/enumerator, the farmer was interviewed on his farm or in his compound. The sociologist's questions then focussed on understanding his position in the household: whether he was head or a member of the male work unit (dabada), or a seasonal migrant (strange farmer); how far he had used, or been able to draw upon, family and hired labour, his means of remunerating them and any reciprocal obligations this entailed; their use of animal drawn equipment and the associated organisation of labour. The differences between rice growing areas and those where women grew only groundnuts also emerged. From the interviewing of the farmers and the asides generated by them and others present at the interviews, important information about the historical development of the project and its administration was also obtained.

There was a price to be paid for carrying out a rapid appraisal within the formal structure described (although it is difficult to see how this could be avoided); some farmers were apprehensive at being visited by a rather large group, including expatriates and project extension staff. The attitude of the extension staff sometimes influenced farmer's responses. Rapport between farmers and visitors varied therefore although the knowledge of local rural economy practices and language by the rural sociologist often led to a relaxation of attitudes. There was probably greater goodwill between farmers and outsiders than if the latter had just 'turned up'.

The lessons to be drawn from this rapid appraisal are not new but are frequently ignored and do not suffer from being repeated. The first is the importance of having one member of the team familiar with the location and comfortable in its surroundings. This applies as much to a person from the country as it does to an expatriate; many 'locals' may have been brought up in an urban area and may not be familiar with the rural areas of their own countryside. An effort by an expatriate to learn a few words of greeting in the local language is important. Indeed even if no member has an intimate knowledge of the local scene (which is often the case) successful rapid appraisals can be carried out if he or she has read the available material extensively, listens to local advice, extends courtesies to potential interviewees (kola nut is used widely as a gift in West Africa) but above all keeps an open mind and avoids succumbing to Western oriented biases in development planning. A major (male?) misconception in project planning is that the family is a homogenous decision making unit: this is clearly not the case, with different members having separate entrepreneurial roles which will strongly influence the distribution of benefits of rural development projects including one involving agricultural production as is the case here. Nor is it necessary to be a sociologist to take such factors into account; indeed all members of an RRA team should aim to do so.

Second, if women's issues are to be investigated, or indeed any matter concerning aspects of family organisation such as nutrition and sexual division of labour then the inclusion of a female investigator is desirable on a rapid appraisal, although existing knowledge could still be used to good effect in her absence. Such areas of investigation are sensitive of course, and it is advisable, as shown in this appraisal, to start with the basic matters of crop cultivation until rapport is established, but to introduce the questions on social relations before the respondent becomes tired with the length of the interview.

Third, cooperation with local appraisals is important to avoid confusion and to share and integrate information. In the absence of the Planning Unit Survey, it would not have been possible to lend quantitative support to the observations of the farmers on the relative profitabilities of cotton and groundnuts nor to check whether the crop yields were satisfactory. Much of the qualitative information would still have been forthcoming, It would have been necessary of course 
to make alternative administrative arrangements for meeting farmers.

\section{References}

Dey, Jennie, 1980, 'Women and Rice in The Gambia: The impact of irrigated rice development projects on the farming system', unpublished $\mathrm{PhD}$ Thesis, University of Reading

The Government of The Gambia/Overseas Development Administration, 1981, The Gambia Food Strategy Report, Parts 1 and 2 